\title{
Peilikäs raanu as a mirror
}

HELENA LONKILA

Helena Lonkila works as a researcher-conservator at the Kainuu Museum. This article is based on the thesis of the same name that the author wrote for her master's degree. She is thus the first person in Finland to have an MA with museology as the main subject. The paper was published by the Department of Art and Culture Studies, University of Jyväskylä, Culture, Science and Technology Master's Programme and the Kainuu Museum in January 2005. The publication is available in Finnish at http://www.kajaani.fi/kainuunmuseo.

One of my tasks as a museum conservator and exhibition copywriter and designer involves work with the physical and visual appearance of objects. In this respect, I have found it important to study which properties of the artefact are referred to in a particular situation and what is considered significant in its essence.

During joint projects on recording the textile heritage in Russian Karelia and creating new products based on it, I have realised that the cultural and especially symbolic values linked with a particular object can be very different, and can also be determined by national background.

I shall discuss the determination of the museum value of one particular object, the Peilikäs raanu from eastern Finland, in the province of Kainuu. I shall study the phenomenon as a process during which the Peilikäs was transformed from an everyday piece of bedclothing to a building material of clear Finnish identity and a symbol of Kainuu folk culture.

\section{TRADITIONAL RAANU}

The Peilikäs raanu used to be a simple rep woven half-woollen quilt, made of such materials as were available for handicrafts, according to traditional patterns. Unlike the decorative raanu textiles of western Finland, the Peilikäs was used as a quilt or blanket. Due to its heavy structure and warm materials, it was most suitable for this purpose.

In the late 19 th and early 20 th centuries, peasant women would tuck up family members, farmhands and visiting friends and relatives under a Peilikäs, regardless of whether they slept in the bedroom, on the floor or on the benches in the living room. A Peilikäs was also a necessity for men, who would use it to cover both their horse and those sitting in a sleigh behind the horse.

In the province of Kainuu, the traditional use and production of Peilikäs raanus went on for a long time. While similar woven fabrics were substituted by decorative raanu wall hangings 
in western Finland in the 19th century, the plain woollen rep woven raanus were used as blankets and quilts in Lapland and Kainuu until the 1950s. This interesting phenomenon is connected with the occasional revival of traditional means of making a living as everyday survival strategies during crises in modern society.

Even though various arts and craft schools and consultation carried out by civic organisations had been spreading new methods, materials, weaving patterns, handicraft textiles and bedclothes in Kainuu since the early 20th century, people would hold on to old practices when they were most needed. This happened, for example, during the depression of the 1930 s and the period of reconstruction in the 1940s. At such times, there were increases in both weaving and the use of traditional textiles.

\section{PEILIKÄS RAANU IN NATIONAL COLLECTIONS}

The first Peilikäs textiles were recorded in the collections of the State Historical Museum, later the National Museum of Finland, during the golden era of collecting Finnish folk culture in the late 19 th century.

In 1894 , inspired by the idea of nationality, architects Yrjö Blomstedt (1871-1912) and Victor Sucksdorff (1866-1952) went to Russian Karelia to study Finnish architecture and collect artefacts of ornamental art. En route to Russia, they changed their initial plan and stopped for a few days in the Finnish province of Kainuu. To their surprise and delight, the two researchers discovered interesting and rare old materials to be studied. In particular, they found the skill of local weavers admirable and local patterns very charming.

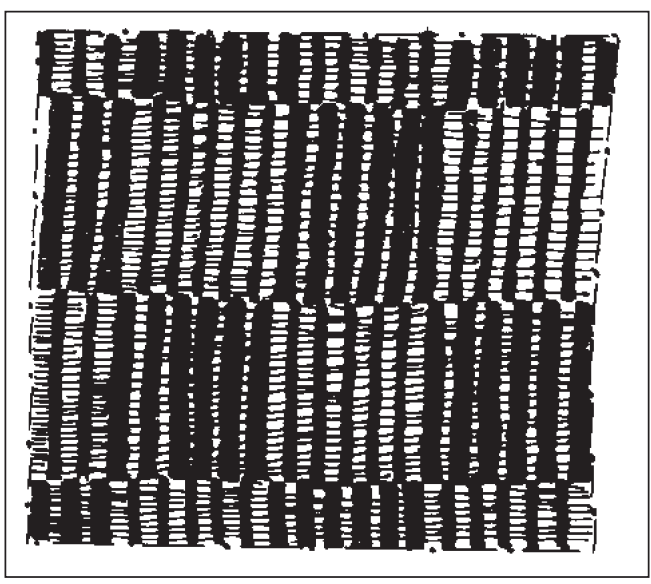

The name of this Peilikäs refers to the surface pattern of the fabric. Squares formed by rep woven stripes of different tones seem to be reflected up and down and to both sides as if by a mirror. As a matter of fact, the word peilikäs is derived from peili, the Finnish for a mirror. A repeat of Peilikäs raanu 1999. Drawing: RIHMA () Anu Heikkinen. Kainuu Museum.

A few years later, Blomstedt and Sucksdorff published a narrative of their journey in two volumes entitled Karjalaisia koristemuotoja keskisestä Venäjän Karjalasta (Karelska byggnader och ornamentala former, Karelian buildings and ornamental forms) in Finnish, Swedish and German.

However, the quilts and drawings collected on the Finnish side of the border did not make their way into the book, and for the most part, the account of their travels in Kainuu also remained unpublished.

As a result, textiles from Kainuu, the Peilikäs raanus among them, were forgotten for over half a decade. Although raanus were collected and studied in other parts of the country, such as Finland Proper, Ostrobothnia, Satakunda and Lapland, publications on folk culture including the Atlas of Finnish Folk Culture 
(1976) - overlooked textiles from Kainuu.

It must also be noted that the collections of Blomstedt and Sucksdorff, located in the National Museum of Finland, had no effect on the general view that there were no elaborate or decorative handicrafts or folk art to be found in eastern Finland.

\section{PEILIKÄS RAANU AS A PRODUCT OF HANDI- CRAFT}

It was not until after the Second World War that the Peilikäs was rediscovered. This time, it was done by developers of handicraft in Finland: the Union of Handicraft, the Handicraft Department of the National Rural Board and handicraft associations, all of which underlined the importance of provincial patterns and products based on them as promoters of national arts and craft skills and means of living. In Kainuu itself, raanu textiles entered the spotlight in 1948 during the 40th anniversary celebrations of the Kajaani handicraft association. The inspector of women's handicraft schools of the National Rural Board, textile researcher Toini-Inkeri Kaukonen, encouraged local school teachers to collect and exhibit old, valuable textiles. In newspaper interviews, she specifically mentioned the Peilikäs raanus, pointing out that they were both genuine and rare examples of fundamentally Finnish folk culture.

After this, the director of the handicraft association, Mrs Salme Tervonen, also took an interest in the matter. As a result of a few years' product development, production of modern raanu textiles based on authentic heritage of the province was started. As a symbol of this production, the genuine handicraft textile from Kainuu, the Peilikäs, was presented.

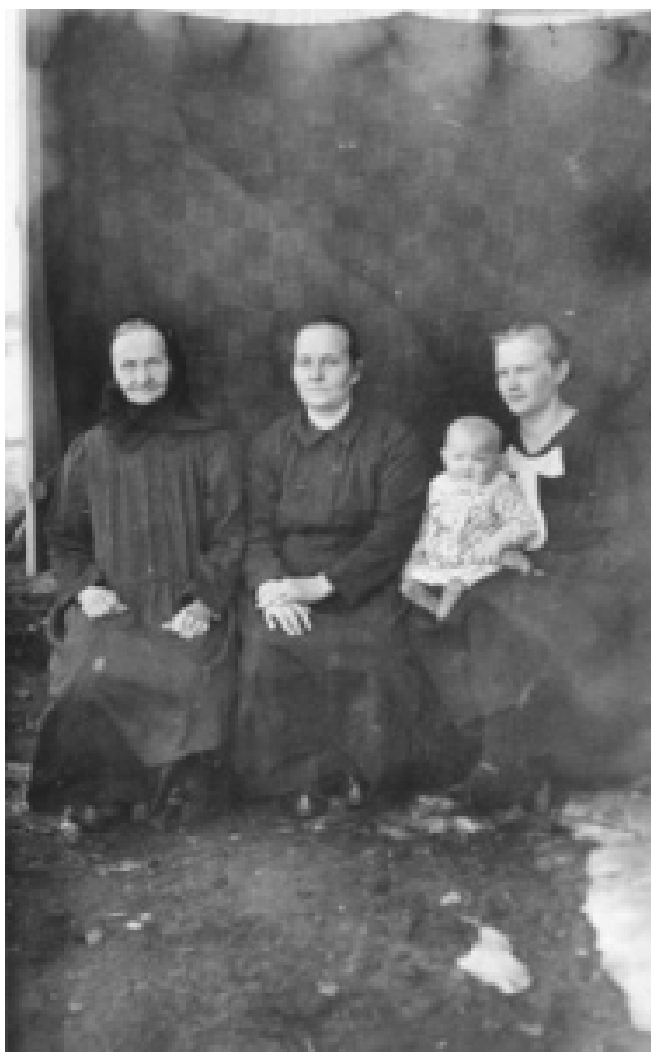

In a family photo taken by Joonas Härkönen in the $1920 s-1930$ s, the women are posing in front of a Peilikäs. Kainuu Museum.

\section{FROM A SWATCH TO MUSEUM COLLECTIONS}

Gradually, the renaissance of raanu, triggered by the handicraft associations, also started to change museum experts' attitudes towards traditional raanus. The very first artefacts to be accepted into museum collections were swatches of traditional raanus and such modern products of handicraft based on them as had proved to be commercially successful. 
The first Peilikäs donated to the Kainuu Museum (in 1956) was a piece of raanu collected for use as a swatch by Bertta Koivula, a teacher of the handicraft school. This was followed by provincial raanu collections designed on the basis of local tradition.

The collections in the National Museum of Finland and local history museums in Kainuu have been enlarged with Peilikäs textiles and pieces of them since the 1960s. The registration work was connected with the post-war revival of provincial spirit and regional research, the goal of which was to preserve the national values threatened by the developments in modern society.

The purpose was not to collect old patterns to be used by modern weavers, but to preserve the raanus as examples of Kainuu handicraft

Fabric samples from Sotkamo, Kuhmo and Lentiira, Finland. Collected by Blomstedt and Sucksdorff in the summer of 1894. Photo: Helena Lonkila.

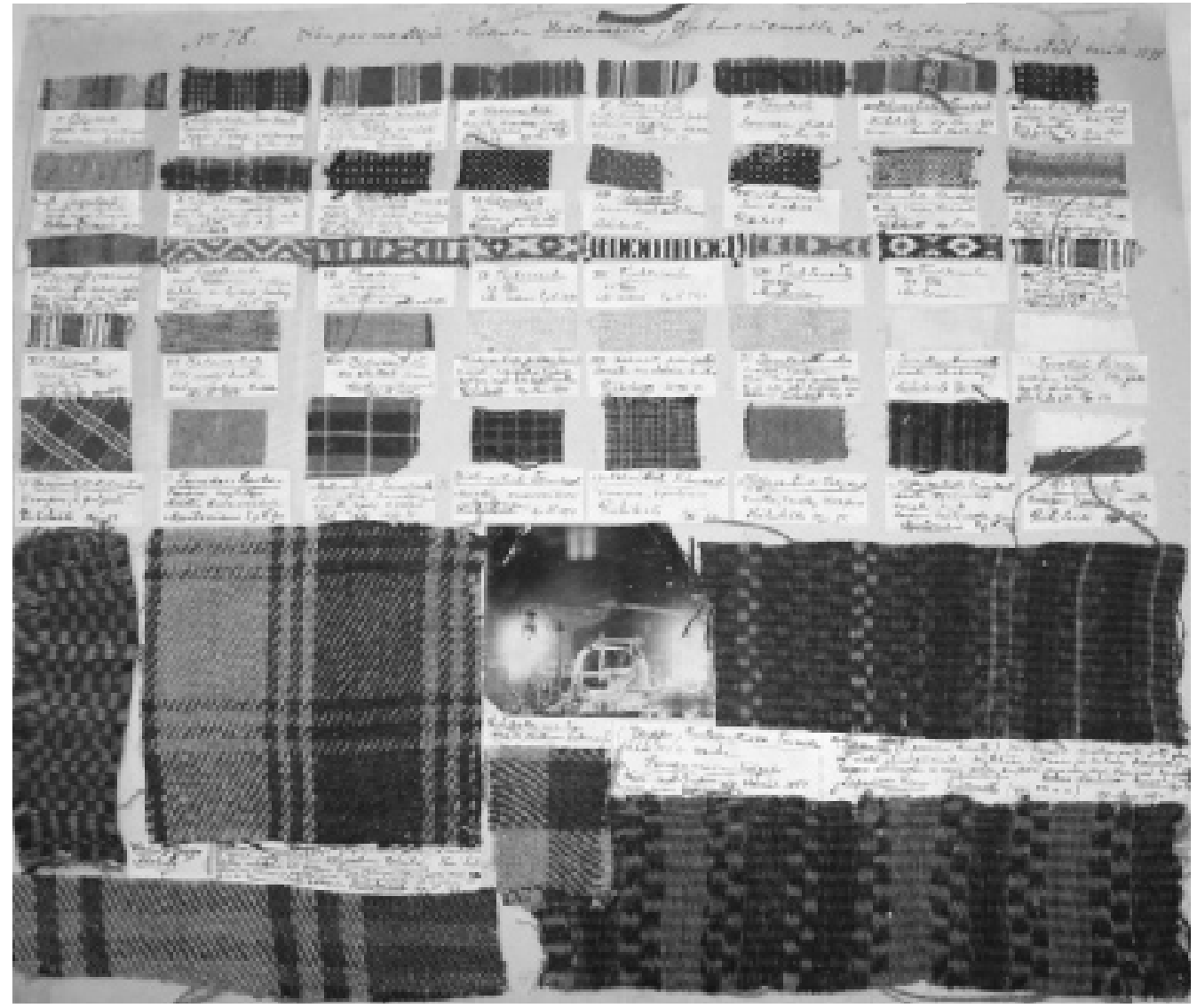


HELENA LONKILA

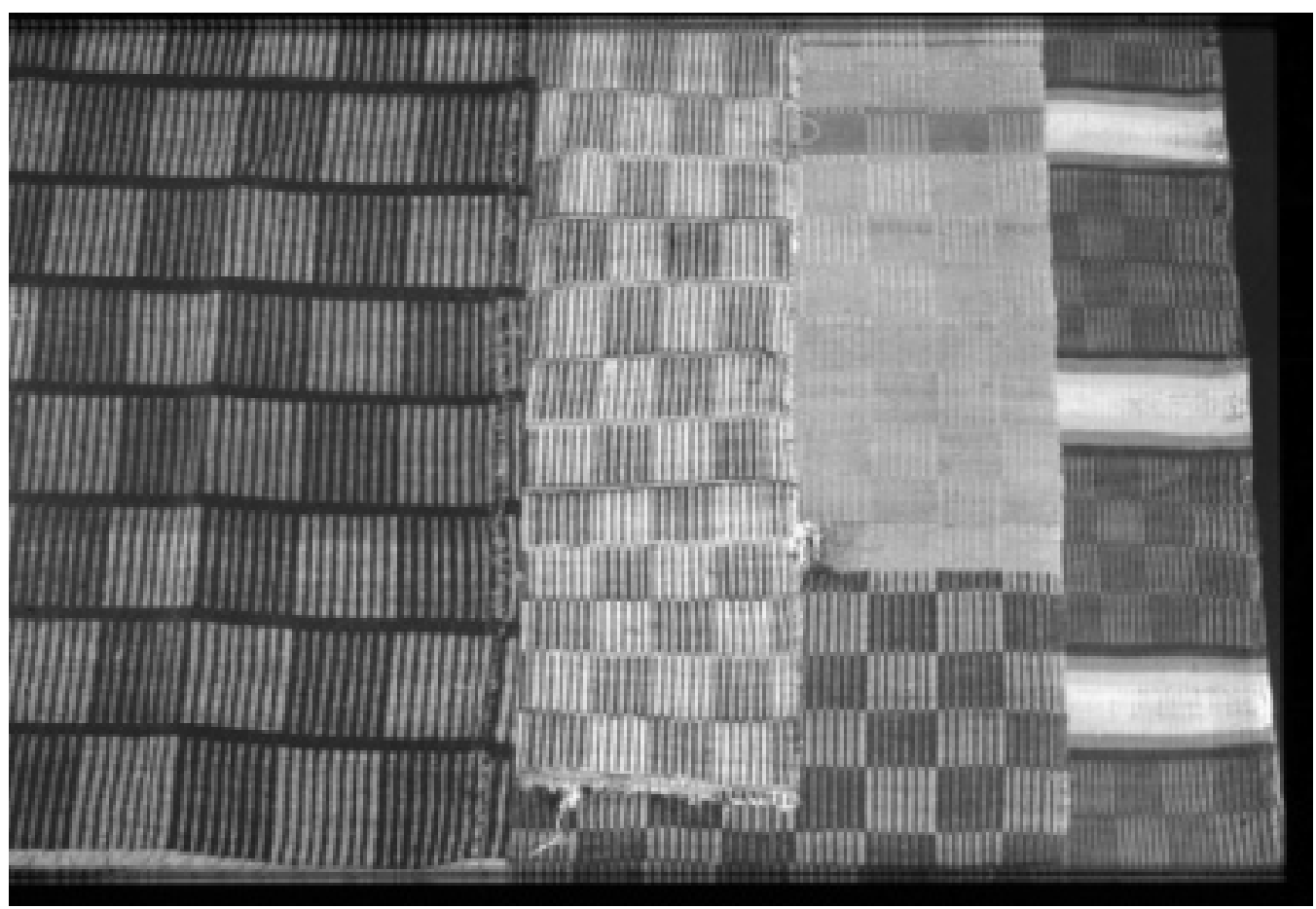

Peilikäs quilts from northern Kainuu, summer 2000. Photo: Helena Lonkila. RIHMA: Kainuu Museum.

furnishings and a disappearing way of life. The collections in the National Museum of Finland were first supplemented with Peilikäs when the Halla house was relocated in 1961 from Kainuu to the Seurasaari Open-Air Museum in Helsinki, the Finnish capital. Halla was furnished with raanus, among other things. Several newly established museums of local history also exhibited the first raanu quilts in the interiors of museum houses.

In the central regional museum, the Kainuu Museum, the value of the Peilikäs was not manifested until the museum was municipalised in 1977. In the permanent exhibition at this new museum, however, Peilikäs was the only textile artefact for which both the production and use were presented in their traditional contexts.

As regional museum work began in the 1980s, the necessity of recording and researching Kainuu textile heritage was recognised and encouraged in the IKI journal, published by the museum. The theme issue of IKI (1/1983) presented several Kainuu raanus mainly as products of handicraft, and depicted the preservation of raanus in the collections of the National Museum of Finland and the Wetterhoff Handicraft Teachers College in Hämeenlinna. Thanks to this publicity, Peili$k \ddot{a}$ started to win public approval. 
The interactive nature of the process of building the cultural value of Peilikäs was manifested by the fact that in the Finnish Weaving Handbook of 1985, the Kainuun Peilikäs was for the first time presented together with other Finnish traditional raanus.

\section{Forming of the museum value of Peili- KÄS RAANU}

The fact that Peilikäs was warm, easy to weave and had several other favourable characteristics promoted its long life in traditional use. The same properties also contributed to the building of its museum value.

Even though the first models of Peilikäs had been recorded in the collections when the national museum was still being established, the definition of folk art and traditional handicraft continued to exclude simple quilts from eastern Finland. The fact that the Peilikäs was in practical use until such a late period also seems to have made it non-historical and considered unworthy of conservation as a museum object.

In the new post-war circumstances, the revi- val of provincial spirit increased the regional craft. Developing the handicraft industry also brought textiles from Kainuu into the spotlight. It was at that time that the Peilikäs became recognised as a genuine part of national handicraft heritage.

The provincial significance of the raanu was manifested in a product called Kainuun Peili$k \ddot{a} s$, which on the one hand, formed a basis for a flourishing business and on the other hand, carried on an old local tradition.

The re-evaluation of the importance of the raanu carried out by the handicraft associations and schools furthered the recognition of the museum value of Kainuu textiles. Peilikäs were recorded as model examples of traditional raanus and design products.

In connection with the Kainuu Museum becoming a municipal institution and the establishment of museums of local history, the museum value of the Peilikäs was linked with the entirety of traditional raanu textiles. Thus, the genuine Finnish and Kainuu properties represented by the raanu approached the interpretation of ordinary people's everyday lives. 